\title{
SEGUNDA MEDITACIÓN TOPOGENÉTICA: LA ARQUITECTURA DE LA LÓGICA PROYECTUAL*
}

\author{
Josep Muntañola Thornberg*** \\ Universidad Politécnica de Catalunya, España
}

Recibido: 28 octubre 2011

Aprobado: 25 noviembre 201 I

Red de relaciones espacio-temporales: Vallespir, siglo XIII. Fuente: suministrada por el autor.

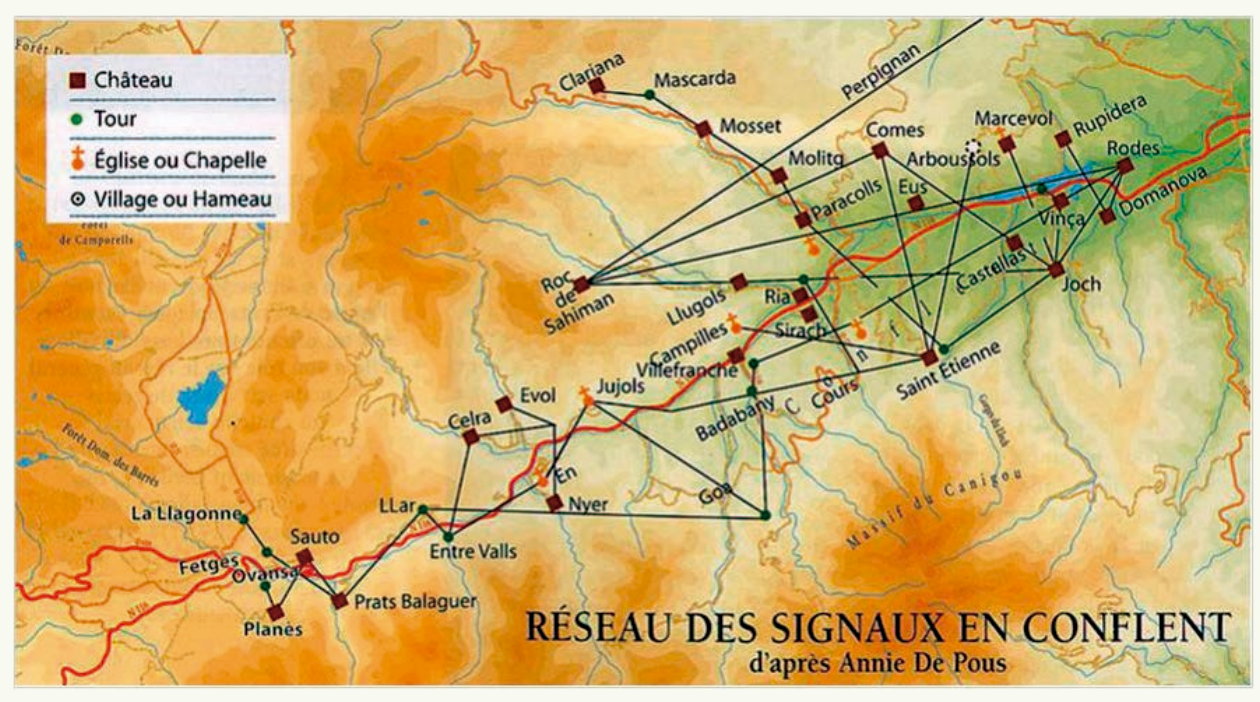

\section{RESUMEN}

Hace años, en un congreso mundial de semiótica realizado en Lyon (International Congress of Semiotics of Space, 2004) escribí la primera meditación Topogenética; ahora llega el momento de la segunda, con el tema de la Arquitectura de la Lógica Proyectual, que ya he iniciado muchas veces, la más reciente en la conferencia inaugural de la Trienal de Arquitectura, en Caracas, en $201 \mathrm{I}$.

El impacto que ha tenido en los arquitectos el último libro de Richard Sennett sobre EI Artesano cuando descubre magistralmente la experiencia que rodea el uso del violín, así como los esfuerzos de J. Pallasmaa (Los ojos de la piel, 2006) por huir de los límites de una arquitectura solo dominada por un orden visual objetivo, me impulsa a proseguir en busca de una lógica proyectual que, sin renunciar a las tecnologías contemporáneas, comprenda su naturaleza práctica, en la que se mezclan ciencias, artes y políticas.

A partir de estos precedentes, intentaré precisar la "lógica" que se esconde bajo el "proyecto" y el acto de "proyectar", con el fin de superar la parálisis de su investigación, debida a una lógica inadecuada y, al mismo tiempo, abrir nuevas perspectivas hacia un análisis del proyecto como herramienta de investigación.

Cuando los arquitectos entendamos lo que significa "proyectar con-textos", comprenderemos enseguida por qué un "proyecto" es un "cronotopo creativo" (o un "creatopo") y, de este modo, podremos volver a ocupar el lugar que nos pertenece con toda la "naturalidad" del mundo.

\section{PALABRAS CLAVE}

Topogenética, Lógica Proyectual, Arquitectura, Proyecto, Cronotopo, 


\section{SECOND TOPOGENETIC MEDITATION: THE ARCHITECTURE OF THE PROJECTIVE LOGIC}

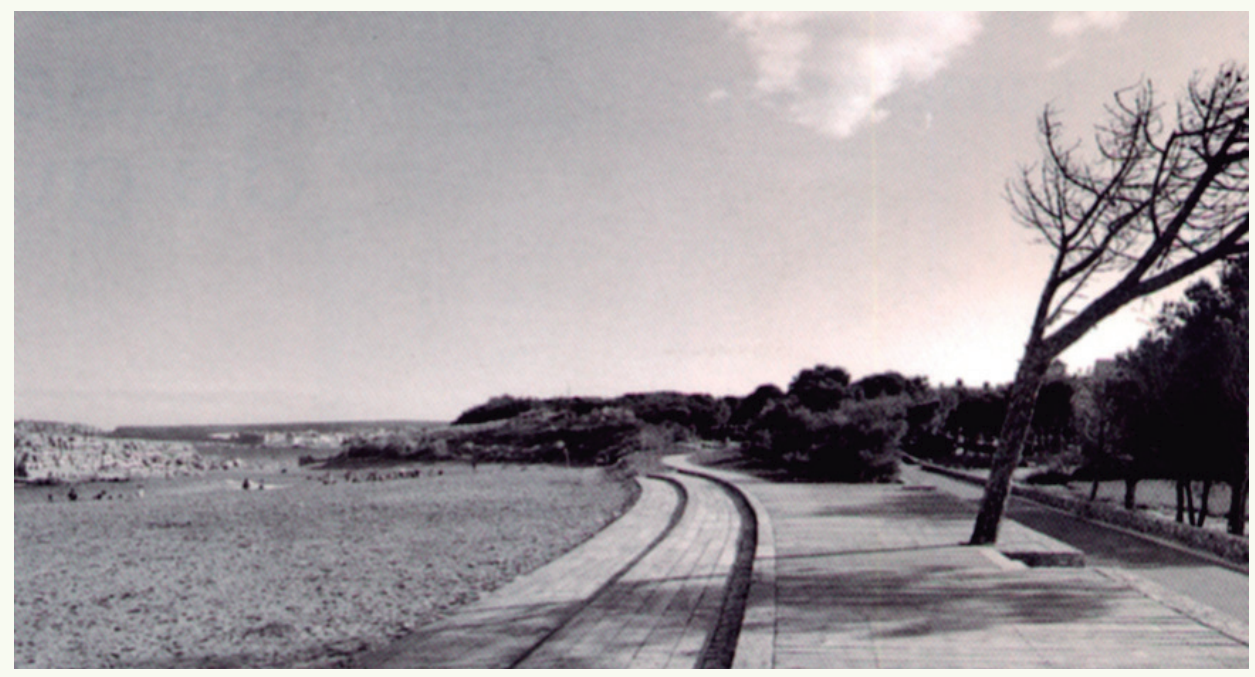

Paseo en Empuries. 1992. (Arquitectos: Magda Saura Carulla, Josep Muntañola Thornberg) Fuente: Suministrada por el autor.

\section{SUMMARY}

Years ago, at a world congress of semiotics in Lyon, I wrote the first Topogenetic meditation, now comes the time to write the second one, with the theme of Projectual Logic Architecture, which I have already started many times, most recently in the inaugural conference of the Triennial of Architecture, in Caracas, in the year $201 \mathrm{l}$.

The impact the last book of Richard Sennett "The Craftsman" has had on the architects, when he brilliantly discovers the experience surrounding the use of the violin, as well as the efforts of J. Pallasmaa to flee out of the limits of an architecture dominated by a objective visual order, impels me to continue in search of a projectual logic that, without renouncing to the contemporary technologies, understands its practical nature, in which science, the arts and policies are blended.

From these precedents, I will try to clarify the "logic" that is hidden under the "project" and the act of "projecting", in order to overcome the paralysis of the research, which is due to an inadequate logic and at the same time, open up new perspectives toward an analysis of the project as a research tool. When we architects come to understand what it means to "project contexts ", we will immediately understand why a "project" is a "creative chronotope" (and a "creatope") and, in this way, we will get back the place which naturally belongs to us.

\section{KEY WORDS}

Topogenetics, Logic Design, Architecture, Project, chronotope 


\section{PRECEDENTES LÓGICOS}

Los precedentes, en mis propios trabajos, vienen de fuentes disciplinares muy diversas que conviene ahora recordar y definir:

a. La escuela de Neuchátel y su Lógica Natural que tanto interesó a un Jean Piaget en sus últimos años activos y que condensa aspectos epistemológicos biológicos, psicológicos y sociológicos'. Es justamente la posibilidad de esta lógica natural, por ordenar dimensiones tanto físicas como socio-culturales, lo que le otorga interés por una lógica proyectual.

b. La imaginación dialógica de Bajtin, y su cronotopo creativo definido poco antes de su muerte, y cuya Lógica Dialógica fue objeto de un nuevo debate en el último congreso de la asociación internacional de Bajtin, en Bolonia, este mismo año ${ }^{2}$, cuando el filósofo italiano G. Bottiroli, de Bergamo, hizo una brillante definición.

c. Por último los esfuerzos valiosísimos de Paul Ricoeur por redefinir una Lógica Hermeneútico-Social, que superara el marco estricto de una semiótica clásica y aceptase la poética y la metáfora, entre otros, como formas de conocimiento, dando así a la relación entre entorno y a la acción con pleno sentido (sensé) que en él se realiza, un valor lógico mucho más intenso y vivo ${ }^{3}$, con la ayuda inapreciable de G. Gadamer.

Entre los tres casos: el de la lógica natural, el de la lógica dialógica y el de la lógica hermenéutico-social, existen aspectos comunes, como que no se busca la lógica en los sujetos o en los objetos (o en los entornos), sino una lógica en las relaciones entre objetos y sujetos, en la que se ubica la génesis del conocimiento ${ }^{4}$.

Figura I. Red de relaciones espacio-temporales: Vallespir, siglo XIII. Fuente: Suministrada por el autor.

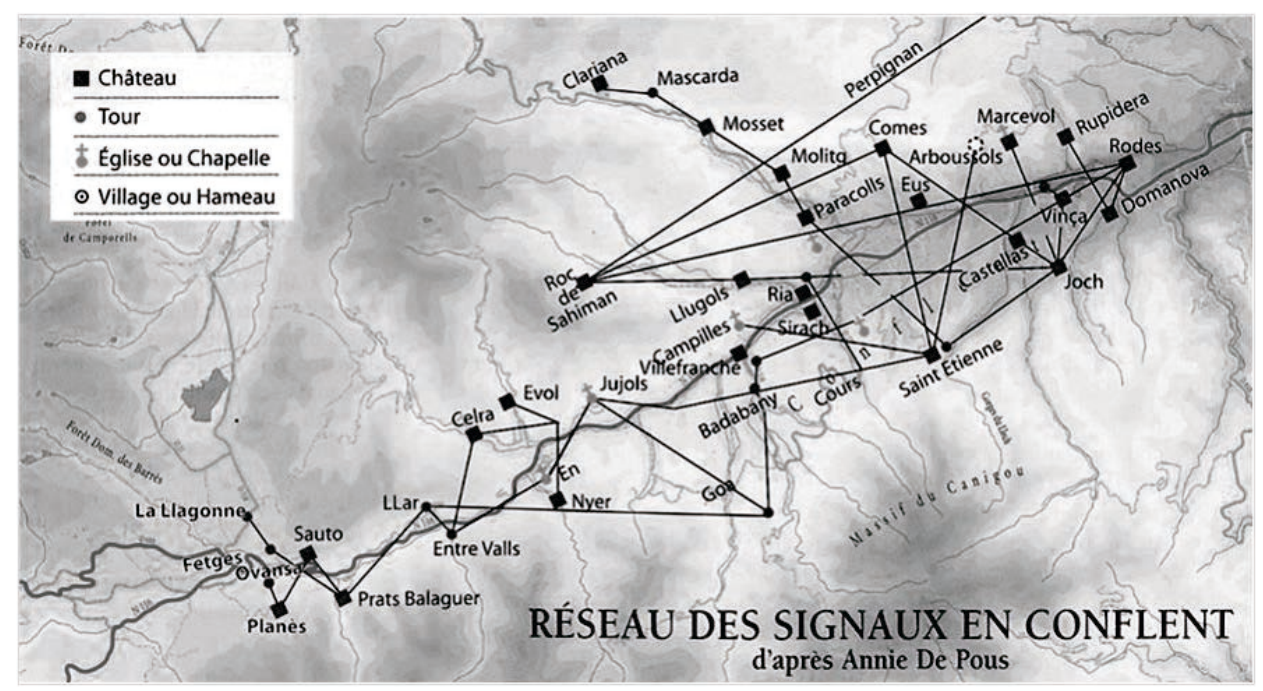

MUNTAÑOLA, Josep. Las formas del tiempo: Arquitectura, educación y sociedad. Editorial Abecedario, 2007

2 MUNTAÑOLA, J., SAURA, M. Bakhtin, architectonics and architecture. XIV International Congress on Bakhtin. Bolonia. Julio. 20II

3 RICOEUR, Paul. Du texte a l'action. Seuil. Paris, 1986

4 MUNTAÑOLA, Josep. Topogénesis. Ediciones UPC. Barcelona. 2006 
No es difícil así, comprobar que las redes hermenéutico-sociales entre sujetos y objetos que se dan en un grupo social cualquiera (ver Gráfico I) en cualquier época, y que pueden encontrarse en hospitales, escuelas, teatros y demás, funcionan con estas tres lógicas, a diferentes niveles de la incorporación (grounding, embodiment) de la abstracción, de acuerdo con el filósofo mejicano Sergio F. Martínez ${ }^{5}$, cuando define distintos niveles de abstracción sobre la misma realidad, con la pregunta abierta de qué existe, finalmente, en común.

Quiero decir, que la "lógica natural" destaca características matemáticas propias de sistemas no formalizados ni tematizados, y que se basan en un proceso dia-lógico abierto $y$, en parte, impredecible. La "lógica dialógica" apunta al juego de identidad poética, retórica, y propiamente dialógica-social, subyacente a una vida social construida por "cronotopos creativos", es decir, por estructuras espacio-temporales que en parte, al menos, construyen una articulación entre sujetos (sociales) y entornos (físicos, geográficos y tecnológicos, entre otros) que puede ser no-reversible, asimétrica, autoconstruida, etc., de modo muy parecido a la "lógica natural" que defiende flujos abiertos y canales de conocimiento diversos.

Por último, la lógica "hermenético-social" de Paul Ricoeur, en su empeño por encontrar un sentido en la labor del arquitecto como autor de un tercer orden espacial, entre dos espacios, el social y el físico, o el del habitar y el de construir, descubre que la arquitectura hace con el espacio lo que un calendario hace del tiempo. Y ya queda claro que es este tercer orden espacial el que contiene la lógica proyectual ${ }^{6}$.

Y así, se llega al punto esencial de esta meditación, al confluir en este discurso, la lógica de un pensamiento del arquitecto que proyecta ${ }^{7}$ con el uso del ordenador y de las máquinas en general, en la arquitectura.

Dos temas de distinta naturaleza, pero que se entrecruzan hoy necesariamente, porque la manera con la que se piensa no es independiente de la manera con que se usan las tecnologías en los proyectos, de ahí el interés de los arquitectos por los trabajos de Sennett, Pallasmaa, y otros.

En cambio, la tesis del determinismo de la tecnología es falsa, porque una cosa es la relación entre la manera de usar la tecnología y la manera de pensar, y otra, es decir, que cada tecnología conlleva una única manera de pensar. Justamente todo lo escrito hasta aquí insiste en la naturaleza interactiva del conocimiento. O sea, que es la interacción entre la manera de pensar y la manera de usar el ordenador donde encontraremos las mejores explicaciones "lógicas".

La paradoja es que es el mismo instrumento, el ordenador, el que puede empobrecer este conocimiento interactivo, como ya anunciaba E. Husserl hace ya casi un siglo ${ }^{8}$ o, por el contrario, el que puede descubrir con gran potencia las razones de este empobrecimiento por su gran capacidad de descripción, análisis, síntesis y representación (si es correctamente "pensado"). (Ver Figura 2).

5 MARTÍNEZ. S., HUANG. X; Epistemic Groundings of Abstraction and Their Cognitive Dimension.(Pendiente por publicar en: Journal of the Philosophy of Science)

6 RICOEUR, Paul. La mémoire, l'histoire, l'oubli. Seuil, 2003

7 MALLGRAVE, H.F; The Architect's Brain: Neuroscience, Creativity, and Architecture. Wiley-Blackwell, 201 I Desgraciadamente su empeño en mantener las teorías de la "Gestalt" como estructuras básicas del diseño no le permite aprovechar las enormes posibilidades neurológicas del texto.

8 HUSSERL. Edmund . L' origine de la géometrie (traducción de Jacques Derrida, Paris: PUF. 1962)

M 43 REVISTA M VOL. 9 No.1. ENERO-JUNIO 2012 • FACULTAD DE ARQUITECTURA • UNIVERSIDAD SANTO TOMÁS COLOMBIA 
Figura 2. Triple estructura cronotópica en la arquitectura.Fuente: Suministrado por el autor

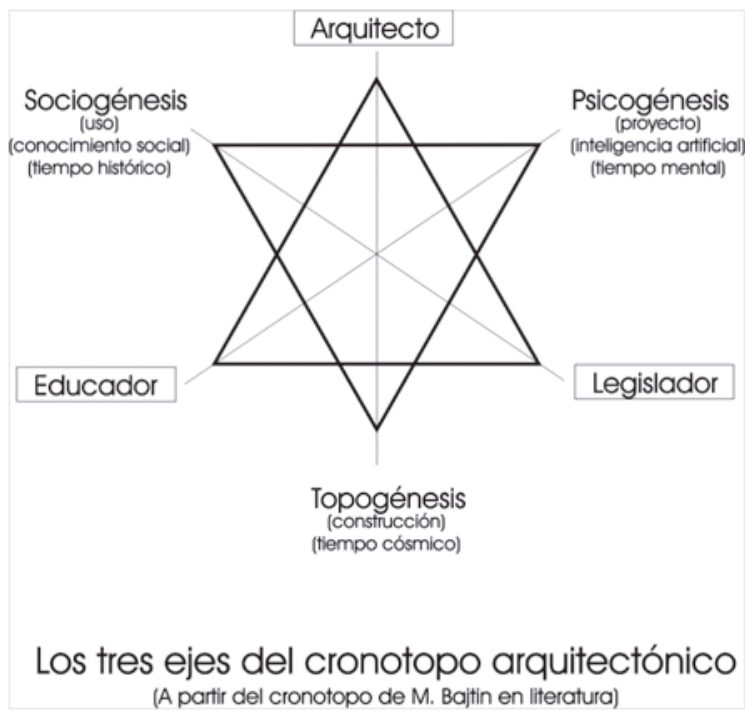

No es por casualidad que las tres lógicas proyectuales descritas tengan orígenes en estudios sobre la evolución biológica (Piaget), la embriología (Bajtin) o el Psicoanálisis (Ricoeur), ya que estamos ante intentos de entender nuestro comportamiento desde nuestra cultura humana física, mental y social, no desde una metafísica sobrehumana fuera del alcance de ciencias, artes y políticas. Es curioso que los textos fundamentales de estos tres autores fueron escritos simultáneamente en 1973, sin que entre los tres autores haya relación documentada alguna (ver Figura 3).
Figura 3. Que pasó en 1973: La Génesis del Cronotopo Creativo. Fuente: Suministrado por el autor
(Subject- Object)

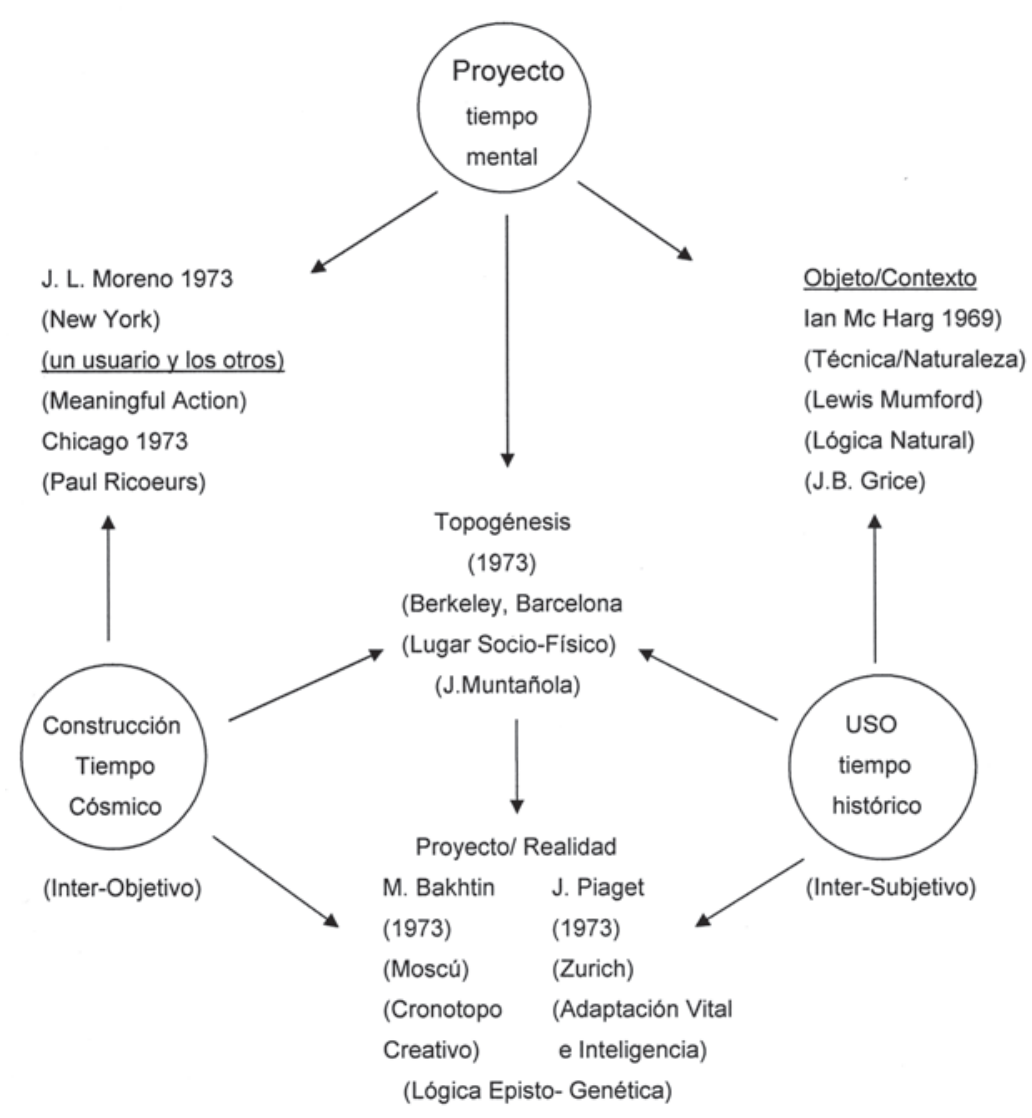




\section{HACIA EL SIGLO XX}

Dicho todo esto, hemos de confesar que sabemos bien poco de la lógica proyectual actual, aunque distintas tesis sobre Carlos Ferrater, Steven Holl, y otros, intentan saber más. Pero el desarrollo de teorías es aún esencial por más datos que tengamos sobre los procesos proyectuales profesionales o de autoconstrucción?.

Si superponemos estas tres lógicas el resultado se acerca mucho a las tesis sobre la heterocronía de conocimiento humano ${ }^{10}$ y sobre una visión de "recapitulación" entre las fases iniciales $y$ las finales de un proyecto. En fin, que se adivina una naturaleza "dialógicacomunicativa" de la arquitectura aunque muy diferente de la lingüístico-verbal a la que estamos acostumbrados $"$. Se trata, como indica Aristóteles, de dar vida a los objetos, no solo a través de lo que dichos objetos significan, o nos evocan, sino a través de las acciones, plenas de sentido en lo individual y en lo social, que en ellos se realizan de forma plena y, hasta en último término, de forma "única". De ahí la importancia del libro de Alberto Magnaghi, recientemente publicado en español, sobre el "Proyecto Local"'2.

La lógica proyectual superpone en un mismo lugar, un único proyecto y unos únicos escenarios, una utopía lógica, que yo he definido como "modernidad específica"|3, pero que subyace en cualquier arquitectura de una forma u otra.

Y sigamos un poco más: si la lógica natural nos describía la tematización matemática de un sistema proyectual, siempre abierta y ambigua, la lógica dialógica nos describe los cronotopos creativos que como las cadenas metafóricas de Steven Holl, hacen inteligible y culturalmente legible aquella tematización abstracto-natural; por último, la lógica hermeneútico-social, nos permite compartir las acciones sociales: fijadas, plenamente significadas y públicas, que caracterizan cada obra de arquitectura, mediante un vaivén entre sujetos y objetos, o entre habitar y construir.

Y si solamente hemos logrado, así, escarbar un poco en esta lógica proyectual, ya hemos hecho muchísimo, tan importante ha sido y es intentarlo.

Lo más interesante, y lo más difícil de entender, en la lógica proyectual en arquitectura, es que bajo la aparente simplicidad de unas geometrías construidas físicamente se esconde una sofisticación cultural y social enorme y una sutil estructura de interacciones sociales llenas de significado. Los arquitectos "vemos" esta sofisticación, pero la explicamos mal, y es la misma que E. Husserl defendió al definir un origen "histórico-social" de la geometría y no un origen autónomo en el mundo metafísico de la virtualidad lógica.

Proyectar es pues, una forma específica de pensar muy diferente del lenguaje inventado para hablar y comunicarse. Proyectar es pensar interaccionando el construir y el habitar $y$, este pensar, contrariamente al verbal, se constituye a través de un proceso comunicativo interno. Por ello es fundamental la estructura de la interacción social entre generaciones, culturas, tiempos históricos, padres a hijos, etc., que los niños usan sistemáticamente en

9 MUNTAÑOLA, J., MUNTANYOLA, D. Architecture in the wild. Architectural research in a digital and global world. ARRC/ EAAE 2010 International Conference, Washington, 23-26 June, 2010. (Pendiente de publicar en: Arquitectonics No. 24. 2012. Barcelona).

I0 LANGER, Jonas, .et al. Early Cognitive Development: Ontogeny and Phylogeny. Handbook of Developmental Psychology. Valsiner \& Connolly Eds., 2003. Pp. 14I-I72

II MUNTAÑOLA, Josep. Poética y Arquitectura. Barcelona: Anagrama, cop. 198I

I2 MAGNAGHI.Alberto. El proyecto Local. Arquitectonics, $n^{\circ} 23$. Ediciones UPC. 20II

13 MUNTAÑOLA, J. Topogénesis. (Op. Cit.)

M 45 REVISTA M VOL. 9 No.1. ENERO-JUNIO 2012 • FACULTAD DE ARQUITECTURA • UNIVERSIDAD SANTO TOMÁS COLOMBIA 
Fotografía I. Paseo en Empuries. 1992. (Arquitectos: Magda Saura Carulla, Josep Muntañola Thornberg) Fuente: Suministrada por el autor

sus concepciones de ciudades ${ }^{14}$. Es la supervivencia de la especie humana la que se relaciona con la arquitectura y el urbanismo: es el espacio-tiempo social y físico, entre sujetos y objetos, o sea, el cronotopo sociofísico al que he hecho ya suficiente referencia a partir de los escritos de J. Piaget, M. Bakhtin y P. Ricoeur.

Entre la naturaleza y un futuro galáctico súper científico, se abre el espacio humano de la supervivencia de la especie y de cómo esta especie sobrevive.

Es desde esta perspectiva que hay que leer el Gráfico 2. Y por ello es tan importante la Dia-lógica de Bajtin basada en los avances de la identidad entre la total identificación hasta la indiferencia absoluta; y en medio, infinidad de "diferencias" posibles.

Cualquier proyecto construido permite comprobar esta complejidad lógica. Selecciono el paseo de Empuries, construido en el año $1992{ }^{15}$ para la llegada de la antorcha olímpica de Grecia para inaugurar las Olimpiadas de Barcelona. (Ver Fotografía I).

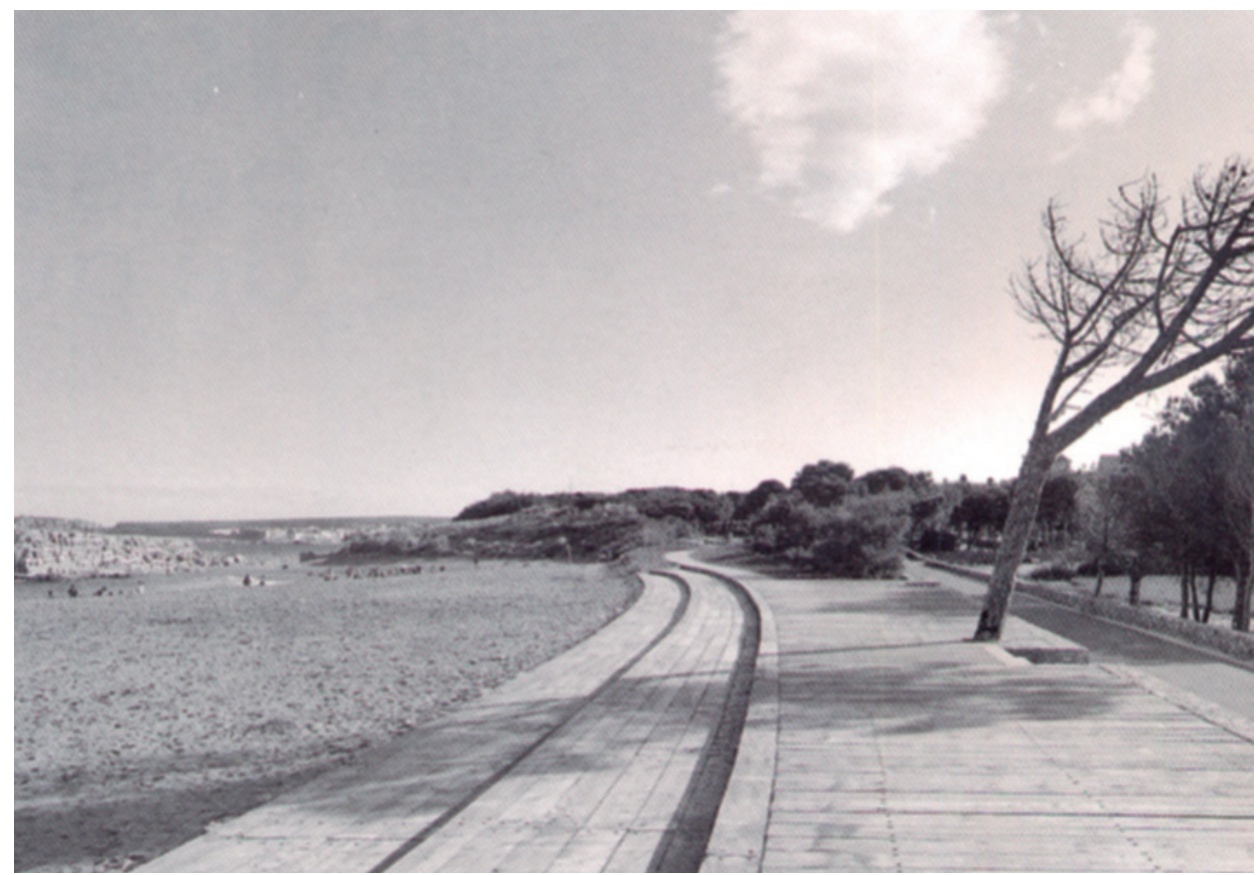

El paseo discurre ente el mar y la ciudad griega antigua, permite un agradable paseo ecohistórico en verano e invierno y, además, tomarse un baño físico, mental y social.

La arquitectura de este paseo es un cronotopo creativo a través del cual la lógica material, la dialogía sociofísica y la hermenéutica social se mezclan en una única experiencia construida por el proyecto y aprobada por años de uso.

Es decir, es una "promenade" arquitectural cuya lógica permite una experiencia única en Europa por su complejidad y simultáneamente por su pequeño tamaño es asequible en pocos minutos a mucha gente.

14 MUNTAÑOLA, Josep. “Le Projet Architectural comme rencontré chronotopique”. En: Nouveaux Actes Semiotiques, No. I II, 2008. (Linoges)

15 Ver "Paseo de Empuries". Quaderns d’Arquitectura, No. 196. Sep-Oct. 1992. Barcelona. 
A partir de este ejemplo, puede verse con más claridad la dialógica que subyace bajo el proyecto arquitectónico que he definido como cronotopo creativo siguiendo el texto póstumo de Mijail Bajtin escrito en el año 1973.

La agudeza de Bajtin consiste en poner de manifiesto la coincidencia, en el cronotopo creativo, entre las tres dimensiones de cualquier objeto cultural humano. Se trata de la relación dialógica entre el autor y la obra (arquitecto y edificio en el caso de la arquitectura), entre la capacidad representativa del objeto y el contexto real geográfico e histórico-social (mundo virtual y mundo real) y entre el usuario real y el usuario virtual del proyecto (usuario potencial y usuario real).

Estas tres dimensiones del cronotopo creativo (Figura 3) pueden analizarse desde una perspectiva científica, artística o política, para evitar confusiones ente ellas, pero en cualquier caso, la lógica proyectual funciona desde la coincidencia antes apuntada.

De este modo, la lógica proyectual, "proyecta”, o mejor "retroproyecta”, simultáneamente, al autor sobre su proyecto, al objeto virtual sobre su contexto real y al usuario sobre el usuario potencial. Esta triple proyección exige una coordinación, síntesis, o “consumación”, entre proyecto, uso y construcción. Las tres lógicas antes definidas: la natural, la hermentica social y la dialógica identitaria, son todas componentes de esta síntesis.

El arquitecto "proyecta” la construcción sobre el mundo real geográfico e histórico social, desde la retroproyección de este mismo proyecto constructivo a partir del otro o usuario potencial, y así la experiencia del arquitecto autor se coordina cronotópicamente con la experiencia del usuario.

El objeto actúa como un enlace entre las dos proyectaciones, y la identificación entre la práctica de la experiencia y la valoración teórica incluida en las diversas "proyectaciones" es evidente (Figura 4),

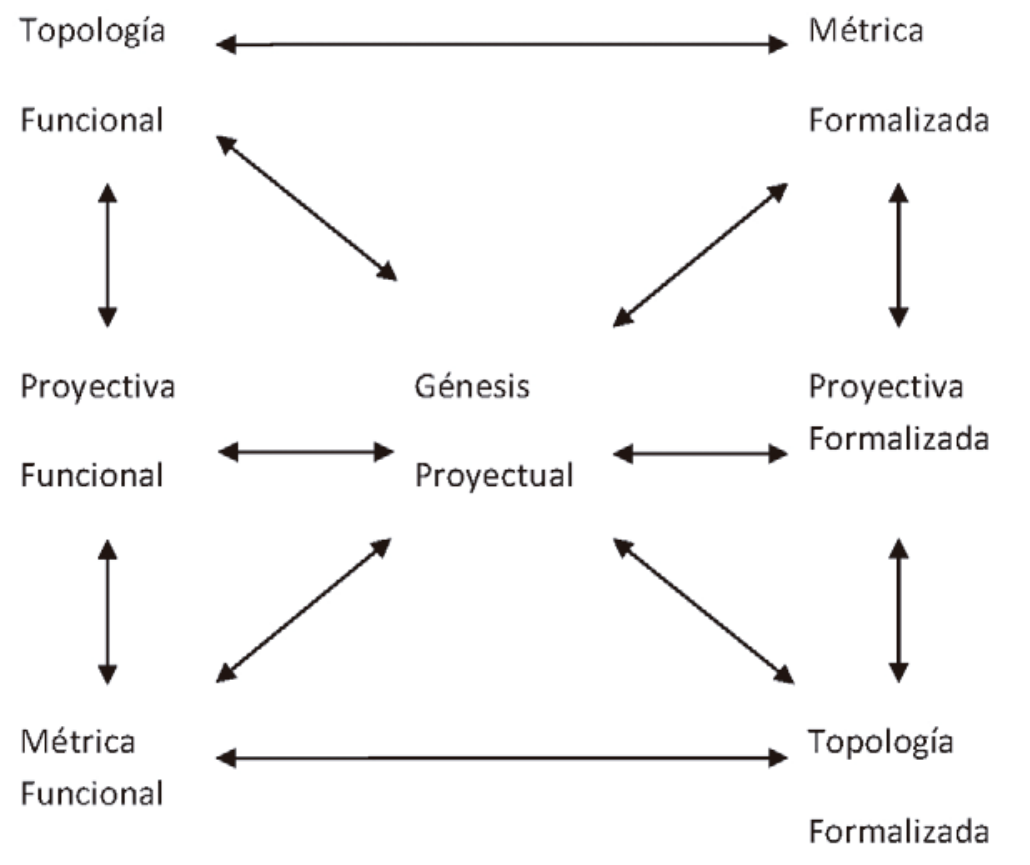

Figura 4. Estructura de la génesis proyectual entre el conocimiento funcional de la realización y el conocimiento formalizado en base a modelos informatizados matemático-geométricos. Fuente: Suministrado por el autor 
para dar la razón al esquema aristotélico entre arquitectura, política social y educación, (Figura 5), esquema que siguió vivo en el siglo XX (Figura 6).

Figura 5. La articulación ética, científica y artística entre arquitectura, educación y política social. Los ajustes y los desajustes entre arquitectos, educadores y políticos marcan la calidad de la vida humana en su conjunto, sin teorías a priori que puedan dar fórmulas seguras. Solo el análisis de lo que ocurre puede ayudar a regenerar esta calidad dentro de unos límites que no son nunca universales Fuente: Suministrado por el autor
Figura 6. Ciudades, Planificadores y Escuelas. En los orígenes del Urbanismo Contemporáneo. Fuente: Suministrado por el autor

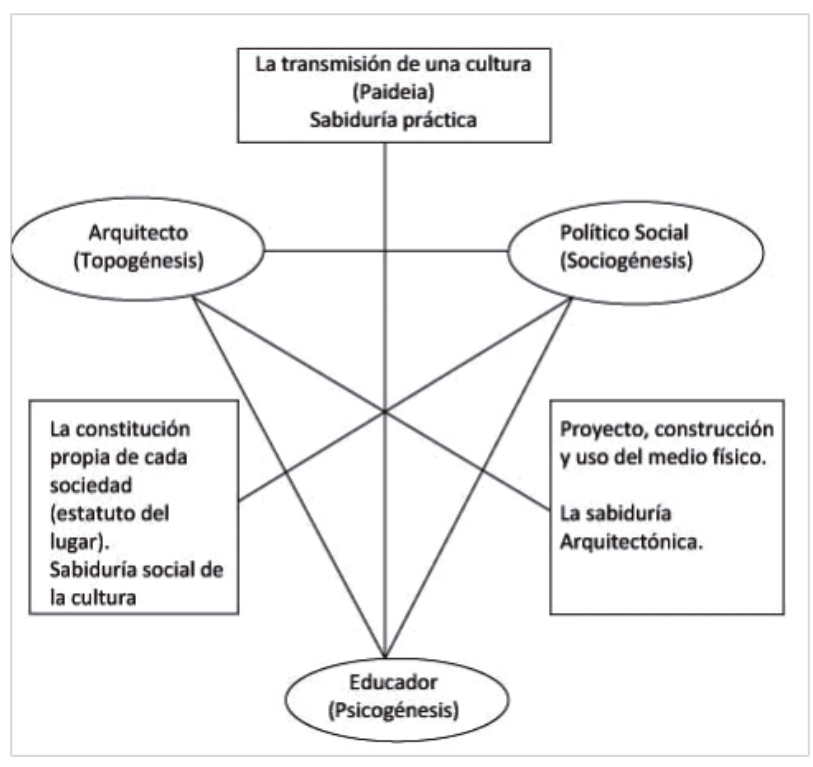


Tal como indiqué en una publicación previa, sobre la poética aristotélica, el reconocimiento social entre sujetos se puede dar a partir de un objeto inanimado que actúa como catalizador de la situación, pero, añade Aristóteles, si la acción que se realiza en relación a este objeto (por ejemplo su uso) forma parte de cómo se experiencia el objeto, mejor que mejor: "la agnición más perfecta es la acompañada por la peripecia, pero hay también otras agniciones, como por ejemplo, con relación a objetos inanimados y a sucesos causales en los que también ocurre como se ha dicho"16

La interdependencia entre la sabiduría educativa, la sabiduría arquitectónica y la sabiduría de la ciudad y de sus leyes sociales, se ve así demostrada, y esta interdependencia es la base de una supervivencia saludable y sostenible. Base que nunca es una garantía definitiva: un terremoto, una guerra, una enfermedad y un accidente, entre otros no pueden nunca descartarse.

Buscábamos la lógica proyectual y hemos encontrado la lógica de la vida humana, no es extraño, ya que, los arquitectos proyectamos lugares, “con-textos”, en los cuales vivir, educar y convivir. Sin embargo, la estructura científica, estética y ético/política, que se puede observar en el Figura 6, está lejos de entenderse y poder ser la base de muchas y valiosas tesis doctorales.

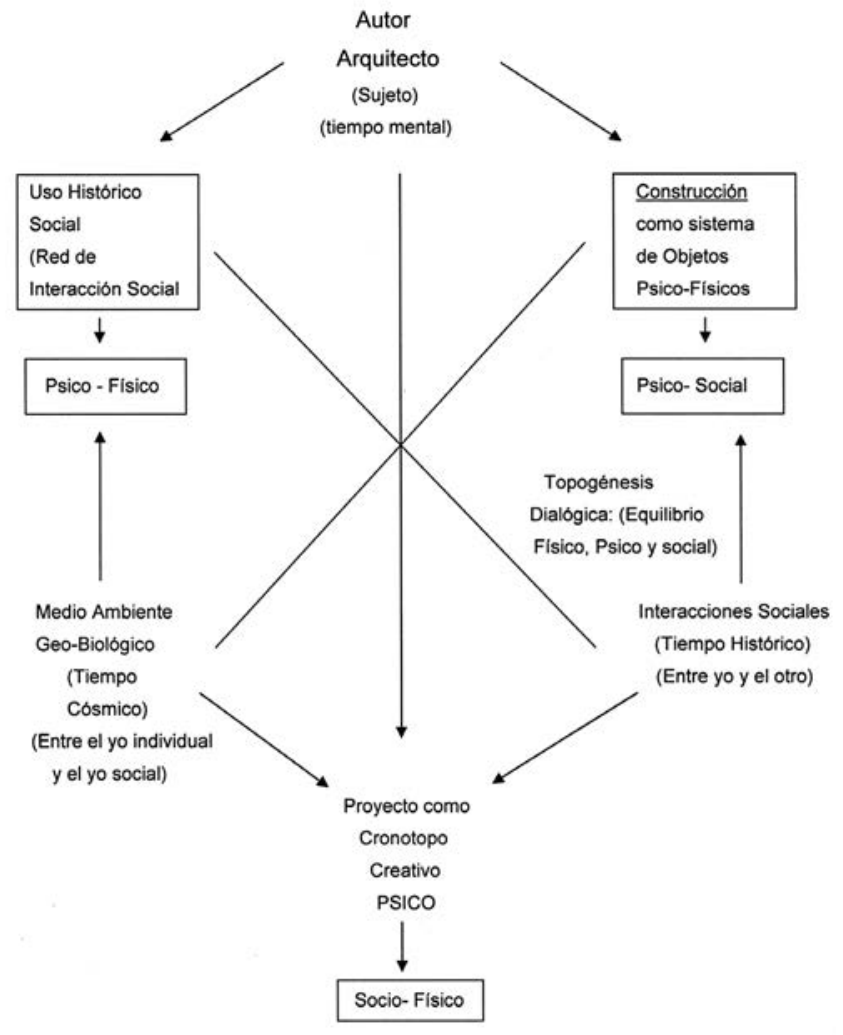

Figura 7. La estructura del Diseño como Cronotopo Creativo: Me imagino en un lugar físico en interacción con otros sujetos, los cuales, a su vez, se imaginan conmigo a través del mismo lugar. De este modo la arquitectura "cataliza" supervivencia entre la mente, el territorio y las relaciones sociales sin identificarse con ninguna. (Existe el yo físico y el yo social) . Fuente: Suministrada por el autor 


\section{BIBLIOGRAFÍA}

HUSSERL. Edmund. L'origine de la géometrie, (traducción de Jacques Derrida, París: PUF. 1962

LANGER, Jonas, et al. "Early Cognitive Development: Ontogeny and Phylogeny". Handbook of Developmental Psychology. Valsiner \& Connolly eds. 2003

MAGNAGHI, Alberto. El proyecto Local. Arquitectonics, No. 23. Ediciones UPC. 201 I

MALLGRAVE, H.F; The Architect's Brain: Neuroscience, Creativity, and Architecture. Wiley-Blackwell, 20II

MARTÍNEZ. S; HUANG. X; Epistemic Groundings of Abstraction and Their Cognitive Dimension.( To appear in Journal of the Philosophy of Science)

MUNTAÑOLA, Josep. First topogenetic meditation. International Congress of Semiotics of Space, Lyon, June, 2004

MUNTAÑOLA, Josep. La investigación proyectual a examen. Trienal de Caracas, 5-12 Junio, 20I I

MUNTAÑOLA, Josep. Las formas del tiempo: Arquitectura, educación y sociedad. Editorial Abecedario, 2007 
MUNTAÑOLA, J., Saura, M; Bakhtin, architectonics and architecture. XIV International Congress on Bakhtin. Bolonia, July 201 I

MUNTAÑOLA, Josep. Topogénesis. Ediciones UPC. Barcelona.2006

MUNTAÑOLA, J., MUNTANYOLA, D. Architecture in the wild. Architectural research in a digital and global world. ARRC/EAAE 2010 International Conference, Washington, 23-26 June, 20I0. (Pendiente por publicar en Arquitectonics No. 24. 20I2. Barcelona).

MUNTAÑOLA, Josep. Poética y Arquitectura. Barcelona. Anagrama. 1981

MUNTAÑOLA, Josep. Le Projet Architectural comme rencontré chronotopique. Nouveaux Actes Semiotiques, No. II I, 2008. (Linoges)

PALLASMAA, Juhani. Los Ojos de la Piel. Gustavo Gili, 2006

RICOEUR, Paul. Du texte a l'action. Seuil. París, 1986

RICOEUR, Paul. La mémoire, l'histoire, l'oubli. Seuil, 2003

SENNET, Richard. The Craftsman. Allen Lane, 2008

M 51 REVISTA M VOL. 9 No.1. ENERO-JUNIO 2012 - FACULTAD DE ARQUITECTURA • UNIVERSIDAD SANTO TOMÁS COLOMBIA 